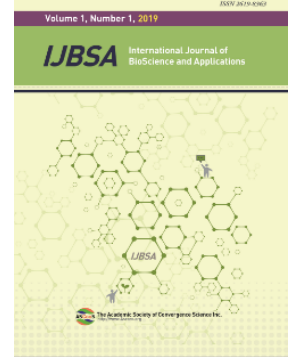

International Journal of

BioScience and Applications

\title{
A Study on the Awareness and Knowledge for Safety Accidents of healthcare workers in Medical Institutions of Korea
}

\author{
Hea Won Lee ${ }^{1}$, Suhyun Kim²* \\ ${ }^{1}$ Doctoral Student, Department of Nursing, Nambu University, 23 Ceomdanjungang-ro, Gwangsan-gu, Gwangju, \\ 62271, Public of Korea \\ ${ }^{2}$ Assistant Professor, Department of Nursing, Nambu University, 23 Ceomdanjungang-ro, Gwangsan-gu, \\ Gwangju, 62271, Public of Korea

\begin{abstract}
${ }^{1}$
Background/Objectives: This study aims to present basic data for developing an intervention strategy to prevent safety accidents in medical institutions of Korea. Methods/Statistical analysis: Data collection was conducted for 197 health workers at four hospitals in 2021. Data analysis was performed using frequency, percentage, independent t-test, ANOVA, Scheffe's test, Pearson's correlation, and multiple regression. Findings: The educational background $(p<.051)$, work experience $(p<.05)$, and salary level $(p<.05)$ were found to have a significant effect on the awareness, and the explanatory power was $10.5 \%$. The educational background $(\mathrm{p}<.001)$, work experience $(\mathrm{p}<.05)$, and salary level $(\mathrm{p}<.05)$ had a significant effect on the knowledge and the explanatory power was $\mathbf{1 3 . 8 \%}$. Improvements/Applications: In the future, it is necessary to develop an intervention program to increase the awareness level and response knowledge of safety accidents among medical institution workers, and repeated studies are needed to identify factors that affect this.
\end{abstract}

\section{Index Terms}

Awareness, Knowledge, Safety Accidents, Health Workers, Korean

\footnotetext{
Corresponding author : Suhyun Kim

Ksh136112@nambu.ac.kr

- Manuscript received July 15, 2021.

- Revised August 10, 2021 ; Accepted September 1, 2021.

- Date of publication September 30, 2021

(c) The Academic Society of Convergence Science Inc.

2619-8363 @ 2021 IJBSA. Personal use is permitted, but republication/redistribution requires IJBSA permission.
} 


\section{INTRODUCTION}

With the development of science and technology, medical services are becoming more complexed and the severity of diseases is increasing, threatening patient safety [1]. Safety accidents that occur in medical institutions not only cause financial loss to the hospital, but also extend the patient's hospital stay and directly affect the patient's health and life [2]. Therefore, healthcare workers should provide medical services with patient safety as the top priority $[3,4]$.

In Korea, the evaluation of patient safety management in hospitals began in 2007 through the evaluation of medical institutions. The medical institution evaluation and accreditation system aims to improve patient safety and quality, and provides detailed standards and guidelines [5]. Recently, studies on patient safety have been attempted in various fields. However, studies targeting medical institutions are not conducted from a holistic point of view. The interest and awareness of patient safety among medical institutions plays a very important role in promoting patient safety [6].

Safety accidents among the areas related to patient safety include economic, physical and mental pain or discomfort due to safety-related injuries such as simple abrasions, bruises, and sharp object cuts, traffic accidents, burns, electric shock, drowning, falls, and falls. It refers to any accident requiring treatment [7]. Awareness level and response knowledge for safety accidents must be preceded in order to prevent safety accidents, so it is necessary to identify factors that affect them.

The purpose of this study is to identify the level of awareness and response knowledge for safety accidents of medical institution workers, and to identify factors affecting the awareness level and response knowledge for safety accidents.

1) Identify the general characteristics of the subject.

2) Identify the subject's awareness level of safety accidents and the level of response knowledge.

3) Compare the average difference between the awareness level of safety accidents and the response knowledge according to the general characteristics of the subjects.

4) Identify the relationship between the subject's awareness level of safety accidents and factors related to response knowledge.

5) Identify factors that affect the subject's awareness level of safety accidents and response knowledge.

\section{MATERIALS AND METHOD}

\section{A. Study Design}

This study is a research study to identify the level of awareness and response knowledge of safety accident workers in medical institutions, and to identify factors affecting the awareness level and response knowledge.

\section{B. Participants}

The subjects of this study were 197 medical institution workers. The sample size of this study was calculated by applying 16 variables, significance level $\alpha=.05$, effect size 0.15 , and power .95 power, in multiple regression analysis using the $\mathrm{G}^{*}$ Power 3.1.7 program. As a result, the number of required subjects was There were 204 patients, but considering the dropout rate of $10 \%, 224$ patients were enrolled. The final 197 copies of the collected questionnaires were analyzed, excluding 27 copies with missing answers.

\section{Research Tool}

1) Awareness of safety accidents

This scale is a scale developed by modifying the checklist and scale of Seung-ryeol Kim and Dongjun Dong (2008) [8] and Yoon-hyeok Yoon (2015) [7]. Awareness of risks in medical institutions, whether to deal with risks when they occur, whether to engage in risk management (safety accident prevention) activities, observation of risk factors, initial response efforts for induced risk accidents, identification and response of risk factors and causes, risk issues (causes) and systematic responses of workers. This scale is a 5-point scale with a total of 12 items, and the higher the score, the higher the awareness level of safety accidents. The reliability Cronbach's $\alpha$ in this study was .952 .

\section{2) Knowledge of safety accidents}

This scale was developed based on the checklist of Seung-ryeol Kim and Dong-jun Dong (2008) [8] and the scale of Yoon Yoon-hyeok (2015) [7]. It consisted of the contents of identifying the knowledge and techniques for identifying risk factors and causes of each type of safety accident, and whether or not education and training were carried out to increase the preventive measures and coping abilities for risks. This scale is a 5-point scale with a total of 12 items, and the higher the score, the higher the risk accident response attitude. The reliability Cronbach's $\alpha$ in this study was .968 .

\section{Data Collection}

The data collection period of this study was from January 14, 2021 to January 28, 2021, for two weeks, 
visiting four hospitals located in J-do for convenient sampling. In order to protect the research participants ethically prior to data collection, those who wish to participate in the survey were selected after obtaining written consent for the purpose and content of the research. In addition, it was explained that the recovered data were processed anonymously and that the participants could withdraw at any time during the survey in consideration of ethical aspects. The confidentiality of the personal questionnaire is protected and not disclosed for purposes other than the research purpose, and the completed questionnaire was discarded after the research was conducted. The questionnaire was filled out by the participant and it took about 15 minutes to fill out.

\section{E. Data Analysis}

Data were analyzed using SPSS/WIN 21.0 program.

1) The general characteristics of subjects were presented as mean, standard deviation, frequency, and percentage.

2) The subject's awareness level of safety accidents and the degree of knowledge in response to safety accidents were presented as minimum, maximum, average, and standard deviation.

3) The difference analysis between the level of awareness of safety accidents and the mean of response knowledge for safety accidents according to the general characteristics of the subjects was analyzed by independent t-test and ANOVA, and the post-test was analyzed by the sheffe's test.

4) The correlation between the subject's awareness level of safety accidents and the knowledge to respond to safety accidents was analyzed by Pearson's Correlation.

5) The predictive factors of the subject's awareness level of safety accidents and response knowledge for safety accidents were analyzed by multiple regression analysis.

\section{RESULT AND DISCUSSION}

\section{A. General Characteristics of the Participants}

The general characteristics of the subjects were as follows. By age, 64 people in their 20s (32.5\%), 54 people in their $30 \mathrm{~s}(27.4 \%), 49$ people in their $40 \mathrm{~s}$ $(24.9 \%)$, and 30 people in their 50 s $(15.2 \%)$ were in that order, and by gender, 188 people $(95.9 \%)$ were female. \%) and 8 males (4.1\%). There were 111 (56.9\%) spouses, 84 (43.1\%) not, $117(60.0 \%)$ not religious, $78(40.0 \%)$ have. The final educational background was 107 people with a bachelor's degree (55.2\%), 71 people with a bachelor's degree or higher $(36.6 \%)$, and 16 people with a high school diploma or less $(8.2 \%)$. 36.1\%), followed by 10 tertiary general hospitals (5.2\%). Work experience: 46 people over 15 years $(23.4 \%), 45$ people with 5 10 years or less $(22.8 \%), 39$ people with 1 to 3 years or less $(19.8 \%), 25$ people with $3-5$ years or less $(12.7 \%), 1023$ people $(11.7 \%)$ with $\sim 15$ years or less and 19 people $(9.6 \%)$ with less than 1 year were found in that order, and the type of work was 117 people $(59.7 \%)$ who worked in shifts and 79 people $(40.3 \%)$ who worked in non-shift work. Salary level was in the order of 77 people $(39.3 \%)$ less than 2 to 2.5 million won, 63 people $(32.1 \%)$ less than $2.5-3$ million won, 36 people (18.4\%) more than 3 million won, and 20 people (10.2\%) less than 1.5-2 million won appear. By occupation, 163 people $(82.7 \%)$ were in nursing, 15 people $(8.0 \%)$ in administrative positions, and 10 people $(5.3 \%)$ as health provider appeared. 173 people $(87.8 \%)$ feel proud of working in a hospital. 137 people $(70.6 \%)$ have solicitation of others for hospital work. 14people $(7.1 \%)$ has experience in arguing with hospital staff $<$ Table $1>$.

\section{Table 1. General Characteristics}

$(\mathrm{N}=197)$

\begin{tabular}{|c|c|c|c|}
\hline Characteristics & Category & $\mathrm{N}$ & $\%$ \\
\hline \multirow{4}{*}{ Age(year) } & $20-29$ & 64 & 32.5 \\
\hline & $30-39$ & 54 & 27.4 \\
\hline & $40-49$ & 49 & 24.9 \\
\hline & Over 50 & 30 & 15.2 \\
\hline \multirow{2}{*}{ Gender } & Female & 188 & 95.9 \\
\hline & Male & 8 & 4.1 \\
\hline \multirow{2}{*}{ Spouse } & Yes & 111 & 56.9 \\
\hline & No & 84 & 43.1 \\
\hline \multirow{2}{*}{ Religion } & Yes & 78 & 40 \\
\hline & No & 117 & 60 \\
\hline \multirow{3}{*}{ Final education } & High school graduate & 16 & 8.2 \\
\hline & College graduate & 107 & 55.2 \\
\hline & University graduate & 71 & 36.6 \\
\hline \multirow{3}{*}{ Type of hospital } & Tertiary general hospital & 10 & 5.2 \\
\hline & General hospital & 112 & 58.6 \\
\hline & Hospital & 69 & 36.1 \\
\hline \multirow{6}{*}{ Working years } & $\leq 1$ & 19 & 9.6 \\
\hline & $1<\leq 3$ & 39 & 19.8 \\
\hline & $3<\leq 5$ & 25 & 12.7 \\
\hline & $5<\leq 10$ & 45 & 22.8 \\
\hline & $10<\leq 15$ & 23 & 11.7 \\
\hline & $<15$ & 46 & 23.4 \\
\hline \multirow{2}{*}{ Type of work } & Shift duty & 117 & 59.7 \\
\hline & Non-shift duty & 79 & 40.3 \\
\hline
\end{tabular}




\begin{tabular}{|c|c|c|c|}
\hline \multirow[t]{4}{*}{$\begin{array}{c}\text { Average } \\
\text { monthly income } \\
(10,000 \text { won })\end{array}$} & $<200$ & 20 & 10.2 \\
\hline & $200 \leq<250$ & 77 & 39.3 \\
\hline & $250 \leq<300$ & 63 & 32.1 \\
\hline & $300 \leq$ & 36 & 18.4 \\
\hline \multirow{3}{*}{ Type of Position } & Nurse & 163 & 82.7 \\
\hline & Officer & 15 & 8 \\
\hline & Health provider & 10 & 5.3 \\
\hline \multirow{2}{*}{ Life with hobby } & Yes & 116 & 58.9 \\
\hline & No & 81 & 41.1 \\
\hline \multirow{2}{*}{$\begin{array}{l}\text { Pride in working in } \\
\text { the hospital }\end{array}$} & Yes & 173 & 87.8 \\
\hline & No & 24 & 12.2 \\
\hline \multirow{2}{*}{$\begin{array}{l}\text { Solicitation of others } \\
\text { for hospital work }\end{array}$} & Yes & 137 & 70.6 \\
\hline & No & 57 & 29.4 \\
\hline \multirow{2}{*}{\multicolumn{2}{|c|}{$\begin{array}{l}\text { Experience in arguing Yes } \\
\text { with hospital staff No }\end{array}$}} & 14 & 7.1 \\
\hline & & 182 & 92.9 \\
\hline
\end{tabular}

\section{B. Degree of Variables}

Satisfaction with the assignment of rest days was 3.65 , life satisfaction was 3.57 , current health was 3.54 , health was 3.38 compared to one year ago, health was 3.47 when compared to others, awareness for safety accidents was 4.02 , and knowledge for safety accidents was 3.84. $<$ Table $2>$.

Table 2. DegreE OF VARIABLES

$(\mathrm{N}=197)$

\begin{tabular}{ccccc}
\hline \hline Variables & $\mathrm{M} \pm \mathrm{SD}$ & Min & Max & Range \\
\hline $\begin{array}{c}\text { Satisfaction of } \\
\text { vacation }\end{array}$ & $3.65 \pm 0.86$ & 1.00 & 5.00 & $1 \sim 5$ \\
\hline Satisfaction of life & $3.57 \pm 0.73$ & 1.00 & 5.00 & $1 \sim 5$ \\
\hline Current health state & $3.54 \pm 0.70$ & 1.00 & 5.00 & $1 \sim 5$ \\
\hline $\begin{array}{c}\text { Health status } \\
\text { compared to one } \\
\text { year ago }\end{array}$ & $3.38 \pm 0.76$ & 1.00 & 5.00 & $1 \sim 5$ \\
\hline $\begin{array}{c}\text { Health status } \\
\text { compared to others }\end{array}$ & $3.47 \pm 0.73$ & 2.00 & 5.00 & $1 \sim 5$ \\
\hline $\begin{array}{c}\text { Awareness for } \\
\text { Safety Accidents }\end{array}$ & $4.02 \pm 0.62$ & 2.58 & 5.00 & $1 \sim 5$ \\
\hline $\begin{array}{c}\text { Knowledge for } \\
\text { Safety Accidents }\end{array}$ & $3.84 \pm 0.73$ & 2.00 & 5.00 & $1 \sim 5$ \\
\hline
\end{tabular}

\section{Differences in awareness and knowledge for} safety accidents according to the general characteristics of subjects

The average comparison according to the general characteristics of the subjects was as follows in Table 3. There was a significant difference in the level of awareness of safety accidents in the final educational background $(\mathrm{p}=.001)$ and work experience $(\mathrm{p}=.013)$. As for the final educational background, those with a bachelor's degree $(M=3.97)$ and a bachelor's degree or higher $(\mathrm{M}=4.20)$ had higher risk perception level scores than those with a high school diploma or lower $(M=3.58)$. It was found that there was a significant difference in the knowledge of response to safety accidents in the final educational background $(\mathrm{p}=.001)$ and work experience $(\mathrm{p}=.009)$. As for the final educational background, those with a bachelor's degree or higher $(\mathrm{M}=4.03)$ and a bachelor's degree or higher $(\mathrm{M}=4.03)$ had higher corresponding knowledge scores than those with a high school diploma or lower $(\mathrm{M}=3.32)$. These results mean that when job training on safety accidents is implemented in medical institutions, the degree of acceptance of the training content and recognition of safety accidents differs according to the level of final academic background, which means that there is also a difference in the knowledge of response to safety accidents. can be found Therefore, rather than job training for generalized safety accidents, it is necessary to differentiate the educational contents by considering the final academic background and work experience. In this study, there was no difference in the level of awareness of safety accidents and response knowledge by job type.

Table 3. DiffEREnCE OF VARIABLES

$(\mathrm{N}=197)$

\begin{tabular}{cccc}
\hline \hline \multirow{3}{*}{ Characteristics } & Category & $\begin{array}{c}\text { Awareness for } \\
\text { Safety } \\
\text { Accidents }\end{array}$ & $\begin{array}{c}\text { Snowledge for } \\
\text { Accidents }\end{array}$ \\
\hline \multirow{5}{*}{ Age(year) } & $20-29$ & $3.91 \pm 0.64$ & $3.79 \pm 0.74$ \\
& $30-39$ & $4.04 \pm 0.66$ & $3.86 \pm 0.75$ \\
& $40-49$ & $4.02 \pm 0.51$ & $3.86 \pm 0.61$ \\
& Over 50 & $4.21 \pm 0.66$ & $3.89 \pm 0.83$ \\
& $\mathrm{~F}(\mathrm{p})$ & $1.575(.197)^{\dagger}$ & $.182 \mathrm{I}(.908)$ \\
\hline \multirow{4}{*}{ Gender } & Female & $4.01 \pm 0.61$ & $3.83 \pm 0.71$ \\
& Male & $4.09 \pm 0.77$ & $3.92 \pm 0.95$ \\
& $\mathrm{t}(\mathrm{p})$ & $-.371(.711)$ & $-.316(.752)$ \\
\hline & Yes & $4.06 \pm 0.59$ & $3.86 \pm 0.71$ \\
& No & $3.96 \pm 0.66$ & $3.81 \pm 0.75$ \\
& $\mathrm{t}(\mathrm{p})$ & $1.075(.284)$ & $.489(.625)$ \\
\hline \multirow{4}{*}{ Religion } & Yes & $4.09 \pm 0.61$ & $3.98 \pm 0.68$ \\
& No & $3.97 \pm 0.62$ & $3.75 \pm 0.74$ \\
& $\mathrm{t}(\mathrm{p})$ & $1.308(.192)$ & $2.234(.027)$ \\
\hline \multirow{4}{*}{ Final education } & High school & $3.58 \pm 0.49^{\mathrm{a}}$ & $3.32 \pm 0.73^{\mathrm{a}}$ \\
& graduate & & \\
& College & $3.97 \pm 0.60^{\mathrm{b}}$ & $3.80 \pm 0.64^{\mathrm{b}}$ \\
& graduate & & \\
& University & $4.20 \pm 0.64^{\mathrm{b}}$ & $4.03 \pm 0.79^{\mathrm{b}}$ \\
& graduate & $7.625(.001)$ & $6.911(.001)$ \\
\hline & $\mathrm{F}(\mathrm{p})$ & & \\
\hline & & &
\end{tabular}




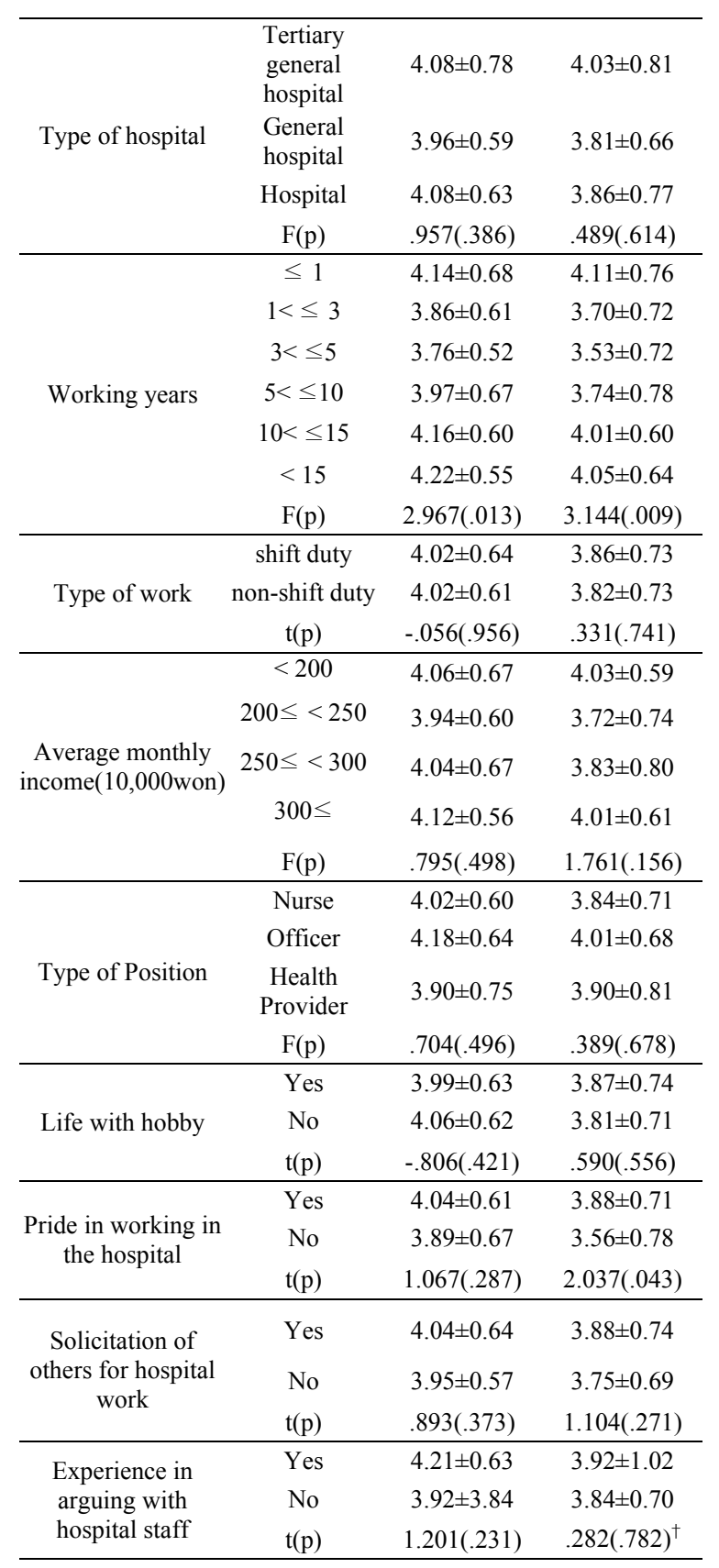

\section{Correlation among Variables}

According to the correlation analysis result, the level of awareness of safety accidents showed a positive correlation in satisfaction with the assignment of rest days $(\mathrm{r}=.144)$, and the knowledge of response to safety accidents showed a positive correlation in satisfaction with life $(\mathrm{r}=.153)$. showed in Table 4. These results show that when work and rest are in balance, awareness of safety accidents can be increased, and it is necessary to consider that excessive workload and poor working environment can lower awareness of safety accidents. Although there are limitations in comparing the research results because there are no studies using the same tools as in this study, in the previous study [9], there was a significant positive correlation between the knowledge and attitude of caregivers about safety, and the attitude toward safety It has been shown to affect safety performance.

Table 4. CORRElation AMONG VARIABLES

$(\mathrm{N}=197)$

\begin{tabular}{rrrrrrr}
\hline \hline $\mathrm{A}$ & $\mathrm{B}$ & $\mathrm{C}$ & $\mathrm{D}$ & $\mathrm{E}$ & $\mathrm{F}$ & $\mathrm{G}$ \\
\hline & $\mathrm{r}(\mathrm{p})$ & & & \\
\hline
\end{tabular}

\begin{tabular}{|c|c|c|c|c|c|c|c|}
\hline A & 1 & & & & & & \\
\hline B & $.474^{* * *}$ & 1 & & & & & \\
\hline C & $.364^{* * *}$ & $.574^{* * *}$ & 1 & & & & \\
\hline D & $.341^{* * *}$ & $.503^{* * *}$ & $.743^{* * *}$ & 1 & & & \\
\hline E & $.305^{* * *}$ & $.499^{* * *}$ & $.765^{* * *}$ & $.751^{* * *}$ & 1 & & \\
\hline F & $.144^{*}$ & .084 & .072 & .069 & .037 & 1 & \\
\hline G & .121 & $.153^{*}$ & .128 & .126 & .070 & $.813^{* * *}$ & 1 \\
\hline
\end{tabular}

\section{E. Predictors on Awareness and Knowledge for Safety Accident}

Multiple regression analysis was performed on the effect on the knowledge for safety accidents. For regression analysis, autocorrelation of the dependent variable and multicollinearity between independent variables were reviewed. Durbin-Watson index was used for autocorrelation, and VIF index was used for multicollinearity.

The Durbin-Watson index of the awareness for safety accidents was 2.064 , the knowledge for safety accidents was 2.009 , and the elderly care behavior was 1.922 independent $(=1.886)$ without autocorrelation. As there was no liver multicollinearity, this data was appropriate for regression analysis.

As a result of multiple regression analysis on the effect on the awareness of safety accidents, educational background $(p<.051)$, work experience $(p<.05)$, and salary level $(p<.05)$ were significant in the awareness for safety accidents. As for education, those with a bachelor's degree or higher $(B=.717)$ had a higher level of risk awareness than those with a bachelor's degree or higher $(\mathrm{B}=.717)$, and those with less than 3 to 5 years of work experience $(B=-.411)$ had 1 year of work experience. Recognition level was lower than below. As for the salary level, less than $2.5 \sim 3$ million won $(B=-.380)$ and 3 million won or more $(\mathrm{B}=-.553)$ showed a low level of awareness. The explanatory power to explain the level of awareness of safety accidents was found to be $10.5 \%$.

As a result of multiple regression analysis on the effect on the knowledge for safety accidents, 
educational background $(\mathrm{p}<.001)$, work experience $(\mathrm{p}<.05)$, and salary level $(\mathrm{p}<.05)$ were significantly higher in knowledge for safety accidents. As for educational background, those with a bachelor's degree or higher $(\mathrm{B}=.877)$ had higher corresponding knowledge than those with a bachelor's degree or lower, and those with less than three to five years of work experience $(B=-.611)$ had less than one year. It was found that those with a salary of less than 2 million to less than $250(\mathrm{~B}=-$ $.481)$, less than 2.5 to 3 million won $(\mathrm{B}=-.566)$, and more than 3 million won $(\mathrm{B}=-.588)$ had lower response knowledge than less than 2 million won. The explanatory power of these variables explaining the corresponding knowledge was $13.8 \%$. As there was no collinearity, this data was suitable for regression analysis $<$ Table $5>$.

Table 5. Predictors on Awareness And KnOwledge for SAFETY ACCIDENT

$(\mathrm{N}=197)$

\begin{tabular}{|c|c|c|c|c|c|c|}
\hline & \multicolumn{3}{|c|}{$\begin{array}{l}\text { Recognition for } \\
\text { safety accidents }\end{array}$} & \multicolumn{3}{|c|}{$\begin{array}{l}\text { Knowledge for } \\
\text { safety accidents }\end{array}$} \\
\hline & $\mathrm{B}$ & $\beta$ & $\mathrm{p}$ & $\mathrm{B}$ & $\beta$ & $\mathrm{p}$ \\
\hline Constant & 3.341 & & $<.001$ & .097 & & $<.001$ \\
\hline Religion(Yes) ${ }^{*}$ & .007 & .005 & .946 & .101 & .068 & .364 \\
\hline $\begin{array}{l}\text { Final education } \\
\text { (College graduate) }\end{array}$ & .535 & .427 & .003 & .705 & .482 & .001 \\
\hline $\begin{array}{l}\text { Final education } \\
\text { (University graduate) }^{*}\end{array}$ & .717 & .555 & $<.001$ & .877 & .581 & $<.001$ \\
\hline $\begin{array}{l}\text { Working } \\
\text { years(1 3yrs) }\end{array}$ & -.281 & -.177 & .126 & -.345 & -.186 & .101 \\
\hline $\begin{array}{l}\text { Working } \\
\text { years(3 5yrs) }\end{array}$ & -.411 & -.224 & .029 & -.611 & -.285 & .005 \\
\hline $\begin{array}{l}\text { Working } \\
\text { years }(5 \sim 10 \mathrm{yrs})\end{array}$ & -.100 & -.067 & .573 & -.314 & -.178 & .125 \\
\hline $\begin{array}{l}\text { Working } \\
\text { years }(10 \sim 15 \mathrm{yrs})^{-w}\end{array}$ & .093 & .049 & .659 & .010 & .005 & .966 \\
\hline $\begin{array}{l}\text { Working years } \\
\text { (15yrs over) }{ }^{* *}\end{array}$ & .216 & .148 & .319 & -.061 & -.035 & .807 \\
\hline $\begin{array}{l}\text { Monthly salaries } \\
(200-250)\end{array}$ & -.257 & -.201 & .114 & -.481 & -.321 & .010 \\
\hline $\begin{array}{l}\text { Monthly salaries } \\
(250-300)\end{array}$ & -.380 & -.286 & .041 & -.566 & -.364 & .008 \\
\hline $\begin{array}{l}\text { Monthly } \\
\text { salaries(300over) }{ }^{-3}\end{array}$ & -.553 & -.349 & .015 & -.588 & -.318 & .024 \\
\hline $\begin{array}{l}\text { Pride in working in the } \\
\text { hospital(Yes) }^{*}\end{array}$ & .141 & .076 & .406 & .259 & .119 & .184 \\
\hline $\begin{array}{l}\text { Solicitation of others } \\
\text { for hospital work(Yes) }\end{array}$ & -.061 & -.045 & .626 & -.082 & -.051 & .570 \\
\hline Satisfaction of vacation & .113 & .156 & .084 & .045 & .053 & .549 \\
\hline Satisfaction of life & -.074 & -.087 & .396 & -.006 & -.006 & .950 \\
\hline Current health state & .042 & .047 & .706 & .102 & .100 & .418 \\
\hline $\begin{array}{l}\text { Health status compared } \\
\text { to one year ago }\end{array}$ & .050 & .061 & .604 & .091 & .096 & .409 \\
\hline
\end{tabular}

\begin{tabular}{llllllll}
\hline Health status compared & -.010 & -.012 & 921 & -.080 & -.080 & 503
\end{tabular} to others

$\begin{array}{rcc}\mathrm{F}(\mathrm{p}) & 2.213(.005) & 2.668(.001) \\ R^{\alpha}\left(\propto d_{j} R^{2}\right) & .191(.105) & .221(.138) \\ \left.d_{\left(d_{U}\right)}\right) & 2.064(1.886) & 2.009(1.886)\end{array}$

$d\left(d_{v}\right)$ : Durbin-Watson's auto-correlation coefficient(upper critical limit) "Dummy variable(1: Yes, 0: No)

** Dummy variable(1:College graduate, University graduate, 0 : High school graduate)

*** Dummy variable(1:1 3yrs, 3 5yrs, 5 10yrs, 10 15yrs, 15yrs over, 0: $\leq 1$ year)

***** Dummy variable $(1: 200-250,250-300,300$ over, $0:<200)$

As looked at the factors affecting the awareness and knowledge for safety accidents conducted in this study, educational background, work experience, and salary level affect the awareness and knowledge for safety accidents, so it is important to prevent safety accidents.

As a limitation of this study, there is a limitation in generalizing the results of this study because it was arbitrarily expressed by targeting only caregivers who were conveniently sampled in proximity in one area.

\section{Conclusion}

The purpose of this study is to develop an educational program to increase the awareness level and response knowledge for safety accidents by identifying the level of awareness and response knowledge of medical institution workers and identifying factors that affect the awareness level and response knowledge. An attempt was made to provide the necessary basic data.

In this study, educational background $(\mathrm{p}<.051)$, work experience $(\mathrm{p}<.05)$, and salary level $(\mathrm{p}<.05)$ were found to have a significant effect on the awareness level and response knowledge of safety accidents. The explanatory power to explain the level of awareness of This suggests that it is necessary to differentiate the content composition in consideration of academic background and work experience when composing the job training program for safety accidents.

This study has limitations in generalization because it randomly sampled only the workers of medical institutions in some regions, and this study suggests the following.

First, a repeated study is proposed in relation to various variables that affect the awareness level and response knowledge of safety management of medical institution workers.

Second, it is necessary to develop a job training program that considers factors that affect the level of awareness and response knowledge about safety management of healthcare workers, and propose a study to verify their effectiveness. 
Third, this study proposes a repeated study to verify the validity of the tools used in this study.

\section{REFERENCES}

[1] Vincent, C. A., \& Coulter, A. (2002). Patient safety: what about the patient?. BMJ Quality \& Safety, 11(1), 76-80.

[2] Bates, D. W., \& Singh, H. (2018). Two decades since to err is human: an assessment of progress and emerging priorities in patient safety. Health Affairs, 37(11), 1736-1743.

[3] Boamah, S. A., Laschinger, H. K. S., Wong, C., \& Clarke, S. (2018). Effect of transformational leadership on job satisfaction and patient safety outcomes. Nursing outlook, 66(2), 180-189.

[4] Kim, J. E., Kang, M. A., Ahn, K. E., \& Sung, Y. H. (2007). A survey of nurses' perception of patient safety related to hospital culture and reports of medical errors. Journal of Korean Clinical Nursing Research, 13(3), 169-179.

[5] Kim S. K., Lee, H. J., \& Oh, E. G. (2010). Perceived level and associated factors of patient safety culture among health care providers in an operating room. Journal of Korean Clinical Nursing Research, 16(2), 56-67.

[6] Lee, K. J., Lee, M. R., \& Cho, Y. H. (2008). A study on safety awareness and accidents in elders. Journal of Korean Gerontological Nursing, 10(1), 48-57

[7] Youn. K-H. (2015). A study on the Establishment and Application Outcomes of the Risk Management System Model in the Elderly Care Facility. Ph D dissertion, Busan University.

[8] Park, D. J. (2008). Management Manager's Success Strategies. Soft Strategic Management Research Institute.

[9] Seo, J.-H., \& Jung, E.-Y. (2020). Knowledge and attitude of patient safety, safety performance among caregivers: In nursing home. Journal of the Korea Convergence Society, 11(10), 409-416.

https://doi.org/10.15207/JKCS.2020.11.10.409 